\title{
Variations in levels of IL- 6 and TNF- $a$ in type 2 diabetes mellitus between rural and urban Ashanti Region of Ghana
}

Samuel N. Darko', Denis D. Yar', Ellis Owusu-Dabo ${ }^{1,2^{*}}$, Anthony Afum-Adjei Awuah', Williams Dapaah', Nicholas Addofoh', Samson P. Salifu' ${ }^{1,3}$, Nana Y. Awua-Boateng ${ }^{1}$ and Fred Adomako-Boateng ${ }^{1,4}$

\begin{abstract}
Background: A surge in pro-inflammatory markers, II- 6 and TNF-a, has been associated with type 2 diabetes mellitus (T2DM). However, there is no data on the dynamics of these markers in T2DM Ghanaian populations. The aim of this study was to determine variations in the levels of IL-6 and TNF-a in T2DM patients. This study also examined the associations of IL- 6 and TNF-a with anthropometric measurement and the effect of co-morbidity with hypertension using rural and urban dwellers in the Ashanti region, Ghana.

Methods: A nested case-control design using participants aged 25-70 years consisting of 77 T2DM \pm hypertension patients and 112 controls were selected from a larger study on Research on Obesity and Diabetes among African Migrants (RODAM). Anthropometric measurements, blood pressure and body fat percentage were measured. Fasting blood samples were analyzed for glucose, IL-6 and TNF-a levels.
\end{abstract}

Results: The median level of IL- 6 was significantly higher $(p<0.0001)$ among rural dwellers compared to urban dwellers. Inversely, urban dwellers had significantly higher $(p=0.0424)$ median level of TNF-a compared to rural cases. No significant differences were observed in IL-6 $(p=0.3571)$ and TNF- $\alpha(p=0.2581)$ among T2DM patients compared with T2DM \pm hypertension patients. A weak negative correlation was found between IL-6 and BMI in urban T2DM.

Discussion: The average level of IL-6 was higher in rural T2DM participants compared with those in urban setting. However, higher levels of TNF-a was observed among the study participants with T2DM in urban settings compared to those of rural. In this study, we observed that co-morbidity of hypertension had no significant effect on the levels of IL-6 and TNF-a. We are of the opinion that higher physical activity levels among rural particpants and high obesity levels in urabn participants explain the observation but needs more numbers to validate.

Conclusion: This study revealed that IL-6 levels were higher among rural dwellers than urban while TNF-a levels were higher in urban dwellers than rural in patients with T2DM. There was no association of body fat percentage and body mass index with IL-6 and TNF-a levels. Co-morbidity of hypertension with T2DM had no effect on IL-6 and TNF-a levels.

\section{Background}

Non-communicable diseases (NCDs) are currently a burden for the global health system [1-3]. Previous studies have indicated that sub-Saharan Africa has the highest incidence rate of type 2 diabetes mellitus (T2DM) which is projected to double from 12 million to 24 million by $2030[4,5]$. Low chronic inflammation

\footnotetext{
* Correspondence: owusudabo@kccr.de

'Kumasi Centre for Collaborative Research in Tropical Medicine, Kwame Nkrumah University of Science and Technology (KNUST), Kumasi, Ghana ${ }^{2}$ School of Public Health, KNUST, Kumasi, Ghana

Full list of author information is available at the end of the article
}

associated with T2DM has fueled investigations into pro-inflammatory biomarkers as early indicators for the detection of T2DM to curtail its progression and associated morbidities [6-9]. However, there is a knowledge gap on the effect of co-morbidities such as hypertension and obesity, which are precursors for low-grade chronic inflammation. Also, differences in environmental settings could affect the levels of proinflammatory markers among T2DM patients from an African population. 
Previous studies conducted to assess variations in inflammatory markers associated with type 2 diabetes in urban populations have indicated a significant difference in the levels of interleukin 6 (IL-6) and tumour necrosis factor $\alpha($ TNF- $\alpha)[10,11]$. Nested case-control studies conducted mainly among Caucasian, Asian and specific native populations showed IL- 6 and TNF- $\alpha$ as predictors for T2DM with varied correlations with anthropometric measurements $[7,8,11]$. High prevalence of obesity in urban settings could cause an increase in pro-inflammatory cytokines. IL- 6 and TNF- $\alpha$ have been observed to have a positive association with obesity in urban dwellers [12]. Most of these studies conducted on inflammatory markers associated T2DM have predominantly sampled urban populations $[10,13]$ without comparing the effect of lifestyle and environmental differences on these marker levels in rural settings of same geographical areas. As a result, little is known about variations in pro-inflammatory markers between urban and rural dwellers with T2DM and compared with healthy populations in both settings. Moreover, to date, no study has been conducted on the dynamics of IL-6 and TNF- $\alpha$ among the T2DM Ghanaian population.

Hence, in this study, we assessed the variations in the levels of, IL- 6 and TNF- $\alpha$ in T2DM patients, associations between anthropometric measurement and these proinflammatory markers and the effect of co-morbidity with hypertension among rural and urban dwellers in the Ashanti region, Ghana.

\section{Methods}

\section{Participants}

A nested case-control study using data from a larger study; Research on Obesity and Diabetes among African Migrants (RODAM) [14]. The study data was collected between 2012 and 2014 in a population consisting of Ghanaians aged $25-70$ years. The urban population was recruited from communities in the Kumasi Metropolis (the second most densely populated city in Ghana) and Obuasi Municipality, while the rural participants were from villages in the same region (Ashanti). The procedure for recruiting and interviewing of participants has been published [14].

\section{Sample size and study power}

Sample size of 189 was estimated using the Cochran method with an assumed T2DM prevalence of $14.4 \%$ in Ashanti region, Ghana at $95 \%$ confidence level nested into cases and controls for both rural and urban settings assuming a default study power of $80 \%$ with $\alpha$ of $5 \%$.

\section{Selection criteria}

A case was defined as participant diagnosed with fasting plasma glucose of $\geq 7.0 \mathrm{mmol} / \mathrm{L}$ and plasma glucose value of $\geq 11.1 \mathrm{mmol} / \mathrm{L}, 2 \mathrm{~h}$ after a $75 \mathrm{~g}$ oral glucose tolerance test [15] with or without hypertension. A control for the study was a participant with fasting plasma glucose $\leq 7.0 \mathrm{mmol} / \mathrm{L}$ without hypertension recruited in the study sites. Participants were selected by simple random selection.

Body weight was measured to the nearest $0.1 \mathrm{~kg}$ with a digital scale (SECA 877, UK) after removal of footwear, heavy clothing and pocket contents. Height to the nearest $0.1 \mathrm{~m}$ was measured using a portable stadiometer (SECA 217, UK). Body Mass Index (BMI) was computed as weight in $\mathrm{kg}$ divided by the square of the height in meters $\left(\mathrm{kg} / \mathrm{m}^{2}\right)$. Using appropriate cuff sizes, three blood pressure readings were taken on the left arm with the Microlife $e^{\circ}$ WatchBP $(\mathrm{UK})$ in a seated position with at least 15 min rest. The mean of the three readings was used. Hypertension was defined as blood pressure of $140 / 90 \mathrm{mmHg}$ or more [16]. Body fat\% was estimated using Bioimpedance and analysis with an impedance analyzer (BODYSTAT 1500 MDD, UK).

Written informed consent was obtained from each participant for inclusion for the study while non-consenting individuals and pregnant women were excluded from the study. This study was approved by the Committee for Human Research Publications and Ethics at the School of Medical Sciences, Kwame Nkrumah University of Science and Technology and the Komfo Anokye Teaching Hospital, Kumasi.

\section{Laboratory methods}

Fasting venous blood samples were collected from each participant by a phlebotomist at all study sites. Blood samples collected were manually processed and aliquoted immediately according to standard operational procedures and cryopreserved before transporting to laboratory for analysis as previously described [14]. Fasting blood glucose was determined using the glucose dehydrogenase method with Accu-Chek ${ }^{\circ}$ Perfoma Analyzer (Roche, Germany) with a coefficient of variation of less than $5 \%$ compared to a laboratory chemistry analyzer. Serum samples were analyzed for IL- 6 and TNF- $\alpha$ using highly sensitive sandwich ELISA. IL-6 was measured in blood serum with a highly sensitive sandwich ELISA using Human IL-6 ELISA test kit (BIOO SCIENTIFIC, USA) with minimum detectable concentration of $8 \mathrm{pg} / \mathrm{mL}$ [17]. TNF- $\alpha$ levels were determined using sandwich ELISA test kit with a minimum detection concentration of $12 \mathrm{pg} / \mathrm{mL}$ [18].

\section{Statistical analysis}

Data were entered into Microsoft Excel and statistical analysis performed using Graphpad Prism 5 software. Data normality was tested using D'Agostino and Pearson omnibus normality test. The statistical difference between medians was estimated by the Mann-Whitney 
test. Associations were measured by coefficients of Spearman's partial correlation whiles controlling for age and gender. Differences were considered statistically significant at $p<0.05$.

\section{Results}

Median levels of pro-inflammatory markers within rural and urban settings

The median levels of TNF- $\alpha$ were 258.5 (32.4 - 514.5) in urban T2DM and $188.0(52.5-412.0)$ in rural T2DM participants (Table 1). There were no differences in TNF- $\alpha$ level between cases and controls within the same setting (Table 1). In the urban population, the median level of IL- 6 was elevated among the control group [43.9 $(0.9-716.2)]$ relative to the T2DM cases $(p=0.8327)$.

Table 1 Characteristics of participants and laboratory investigations

\begin{tabular}{|c|c|c|c|}
\hline \multirow[t]{2}{*}{ Variables } & \multicolumn{2}{|l|}{ Median (range)/n (\%) } & \multirow[t]{2}{*}{$p$ value } \\
\hline & T2DM Cases & Controls & \\
\hline Urban & $n=37$ & $n=42$ & \\
\hline Age (years) & $50(27-69)$ & $45.5(31-70)$ & 0.3477 \\
\hline \multicolumn{4}{|l|}{ Sex } \\
\hline Male & $8(22)$ & $5(12)$ & \\
\hline Female & $29(78)$ & $37(88)$ & \\
\hline Height (m) & $1.6(1.5-1.8)$ & $1.6(1.4-1.8)$ & $0.0057^{a}$ \\
\hline Weight (kg) & $66.4(44.5-96.6)$ & $62.5(34.1-93.3)$ & 0.1615 \\
\hline $\mathrm{BMI}\left(\mathrm{kg} / \mathrm{m}^{2}\right)$ & $27.3(20.0-38.7)$ & $26.4(17.7-48.4)$ & 0.1341 \\
\hline Body Fat (\%) & $48.3(25.9-66.5)$ & $48.0(23.8-61.2)$ & 0.9569 \\
\hline Hypertension & $9(23)$ & NA & \\
\hline $\mathrm{FBS}(\mathrm{mmol} / \mathrm{L})$ & $7.5(7.0-18.8)$ & $5.7(4.7-6.6)$ & $<0.0001^{a}$ \\
\hline IL-6 (pg/mL) & $38.7(12.3-129.3)$ & $43.9(8.0-500.0)$ & 0.8327 \\
\hline TNF-a (pg/mL) & $258.5(32.4-514.5)$ & $158.8(14.18-6320)$ & 0.0714 \\
\hline Rural & $\mathrm{n}=40$ & $n=70$ & \\
\hline Age (years) & $51.5(28-70)$ & $49(25-70)$ & 0.3429 \\
\hline \multicolumn{4}{|l|}{ Sex } \\
\hline Male & $19(48)$ & $29(41)$ & \\
\hline Female & $21(52)$ & $41(59)$ & \\
\hline Height (m) & $1.6(1.5-1.2)$ & $1.6(1.2-1.8)$ & 0.2796 \\
\hline Weight (kg) & $59.70(43.35-78.6)$ & $58.1(36.4-101.8)$ & 0.7047 \\
\hline $\mathrm{BMI}\left(\mathrm{kg} / \mathrm{m}^{2}\right)$ & $21.57(9.64-30.5)$ & $20.68(15.8-33.4)$ & 0.5571 \\
\hline Body Fat (\%) & $42.9(26.3-60.28)$ & $43.1(10.7-60.4)$ & 0.8254 \\
\hline Hypertension & $19(51)$ & NA & \\
\hline FBS (mmol/L) & $7.5(7.0-13.7)$ & $6.0(4.6-6.9)$ & $<0.0001^{a}$ \\
\hline IL-6 (pg/mL) & $108.4(26.0$ - 478.0) & $48.3(4.8-432.8)$ & $<0.0001^{a}$ \\
\hline TNF- a $(\mathrm{pg} / \mathrm{mL})$ & $188.0(52.5-412.0)$ & $184.5(53.3-700)$ & 0.5282 \\
\hline
\end{tabular}

T2DM: type 2 diabetes mellitus, BMI: body mass index, FBS: fasting blood sugar, IL-6: interleukin-6, TNF- a: tumour necrosis factor-alpha. NA: not applicable

${ }^{a}$ statistically significant
However, IL-6 levels among the rural population in T2DM cases were significantly higher than in the controls $(p$ value $<0.0001)$.

Median levels of pro-inflammatory markers in T2DM cases between rural and urban settings

IL-6 levels were significantly higher $(p<0.0001)$ among the rural cases compared to those of the urban cases (Fig. 1a). Inversely, urban cases had a significantly higher $(p=0.0424)$ median level of TNF- $\alpha$ compared to rural cases (Fig. 1b).

\section{Measures of adiposity and fasting blood sugar between rural and urban settings}

Both urban and rural dwellers had median age of 50 years (Table 2) with ages ranging from 27 to 70 and $25-70$ respectively $(p=0.8270)$. There were more female participants in the urban $(84 \%)$ setting compared to rural $(56 \%)$ area. Both BMI and body fat percentage were significantly higher in the urban participants compared with those in rural setting ( $p$ values of $<0.0001$ and 0.0002 respectively).

\section{Effect of co-morbidity of hypertension on levels of IL-6 and TNF-a}

There was no association observed in IL-6 $(p=0.3571)$ and TNF- $\alpha \quad(p=0.2581)$ levels in patients with only T2DM compared with patients with T2DM + HTN (Figs. 1c and 1d).

\section{Associations between anthropometric and pro- inflammatory markers in T2DM}

IL-6 was negatively but weakly correlated with BMI $(\mathrm{r}=-0.3765, p=0.0258)$ in the urban study group (Table 3).

\section{Discussion}

There are very limited studies conducted in Ghana to assess the correlation of IL- 6 and TNF- $\alpha$ among T2DM patients with hypertension and non-diabetic participants in rural and urban settings. Our results have showed varying levels of IL- 6 and TNF- $\alpha$ between T2DM cases and controls in both rural and urban settings. The average level of IL-6 was higher in rural T2DM participants compared with those in urban setting. However, higher levels of TNF- $\alpha$ was observed among the study participants with T2DM in urban settings compared to those of rural. In this study, we observed that co-morbidity of hypertension had no significant effect on the levels of IL- 6 and TNF- $\alpha$. To the best of our knowledge, this is the first time a study of this kind has been conducted in Ghana while only limited related studies have been conducted in Africa [19]. The high level of IL-6 observed among T2DM cases from the rural setting is fairly 

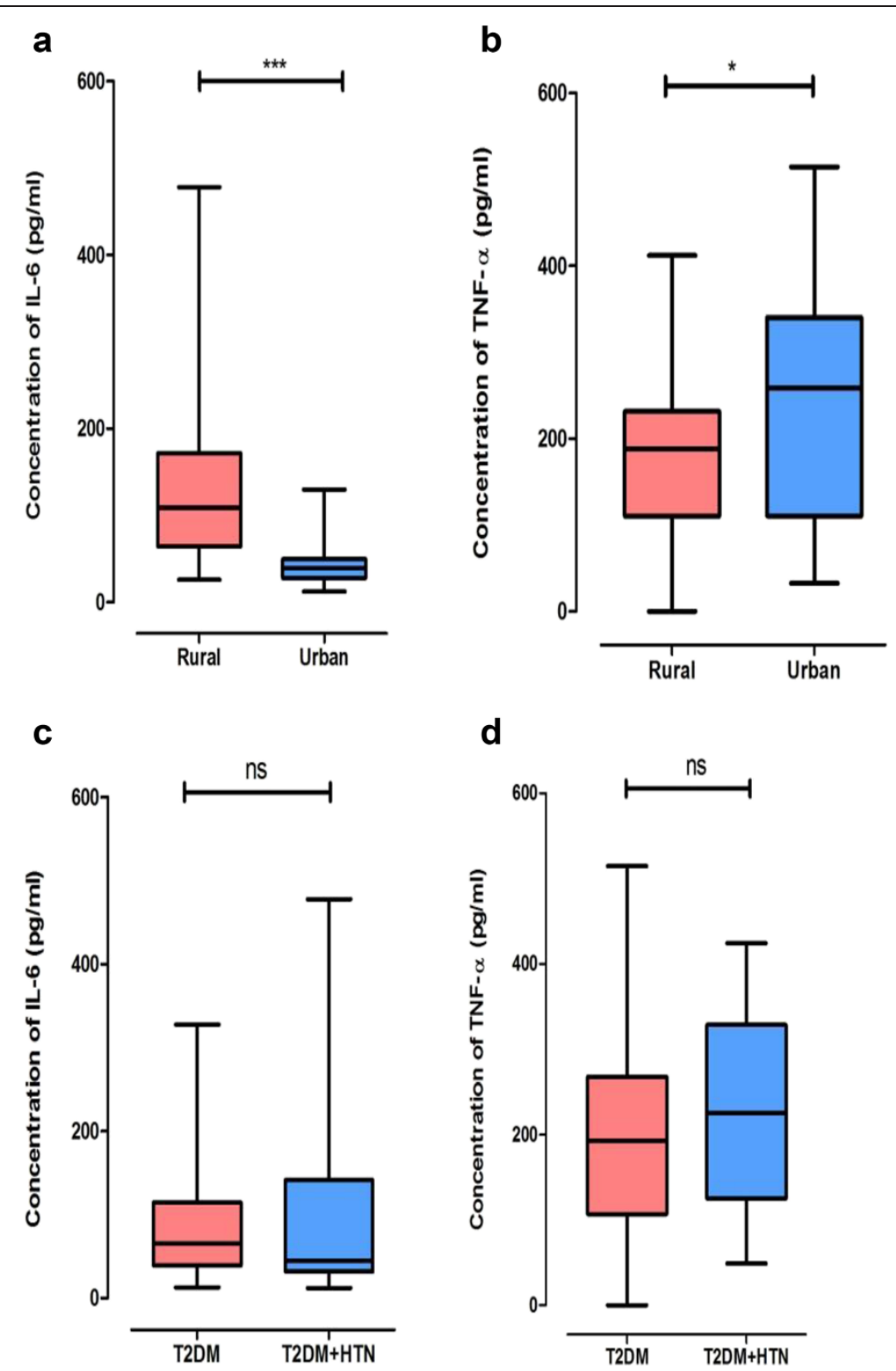

Fig. 1 Variations in levels of pro-inflammatory markers and the effect of hypertension between settings. ${ }^{*} p=0.0424,{ }^{* * *} p<0.0001$, ns $=$ not statistically significant, T2DM + HTN = type 2 diabetes mellitus + hypertension. a Overall levels of IL-6 among rural and urban participants. b Overall levels of TNF-a among rural and urban participants. c Levels of IL-6 among rural and urban participants with only T2DM compared with T2DM and Hypertension. $\mathbf{d}$ Levels of TNF-a among rural and urban participants with both T2DM and Hypertension

similar to what was found in previous studies conducted by Krakoff and Nadeem [7, 10] although these studies were conducted in a native Pima Indians in Mexico and Pakistani populations respectively. However, in a related study by Al-Shukaili et al. (2013) [13] among an urban Asian population, patients with T2DM had decreased levels of IL-6 compared to healthy controls. While a cross-sectional study by Hossain and colleagues found no significant difference in serum levels of IL-6 between pre-diabetic participants and controls [20]. The difference between our findings and these other studies may be attributed to several reasons, including differences in case groups, varying sample sizes, gender composition, differences in environmental and social settings and the duration of the T2DM disease. The significantly higher levels of IL-6 among the rural T2DM compared to urban population observed in our study, we suspect could result from the synergistic effect of pro-inflammatory action of IL-6 in T2DM and its anti-inflammatory myokine action [21] induced by physical exercise. Circulating IL- 6 has been found to increase to about 100 fold in response to physical activity and this is dependent on the intensity, duration and 
Table 2 Measures of adiposity and fasting blood sugar between urban and rural settings

\begin{tabular}{|c|c|c|c|}
\hline \multirow[t]{2}{*}{ Variables } & \multicolumn{2}{|c|}{ Median (range)/n (\%) } & \multirow[t]{2}{*}{$p$ value } \\
\hline & Urban & Rural & \\
\hline & $n=79$ & $n=110$ & \\
\hline Age & $50(27-70)$ & $50(25-70)$ & 0.827 \\
\hline \multicolumn{4}{|c|}{ Age Category (years) } \\
\hline $25-34$ & $6(7.59)$ & $19(17.27)$ & \\
\hline $35-44$ & $24(30.38)$ & $23(20.91)$ & \\
\hline $45-54$ & $27(34.18)$ & $31(28.18)$ & \\
\hline $55-64$ & $16(20.35)$ & $27(24.55)$ & \\
\hline $65+$ & $6(7.59)$ & $10(9.09)$ & \\
\hline \multicolumn{4}{|l|}{ Sex } \\
\hline Male & $13(16)$ & $48(44)$ & \\
\hline Female & $66(84)$ & $62(56)$ & \\
\hline BMI & $27.2(17.7-48.4)$ & $20.9(15.0-33.4)$ & $<0.0001$ \\
\hline \multicolumn{4}{|c|}{ BMI Category (kg/m2) } \\
\hline $\mathrm{BMl}<18.5$ & $4(5.07)$ & $20(18.18)$ & \\
\hline $18.5 \leq \mathrm{BMI} \leq 24.9$ & $25(31.65)$ & $66(60.00)$ & \\
\hline $25.0 \leq \mathrm{BMI} \leq 29.9$ & $27(34.18)$ & $18(16.36)$ & \\
\hline $\mathrm{BMI} \geq 30$ & $23(29.11)$ & $6(5.45)$ & \\
\hline Body Fat $\%$ & $48.1(23.8-66.5)$ & $43.1(10.7-60.4)$ & 0.0002 \\
\hline FBS & $6.5(4.7-18.8)$ & $6.6(4.6-13.7)$ & 0.9400 \\
\hline \multicolumn{4}{|l|}{ FBS Category } \\
\hline $\mathrm{FBS}<6.0$ & $29(36.71)$ & $30(27.27)$ & \\
\hline $6.0 \leq \mathrm{FBS} \leq 6.9$ & $13(16.46)$ & $40(36.36)$ & \\
\hline $\mathrm{FBS} \geq 7.0$ & $37(46.84)$ & $40(36.36)$ & \\
\hline
\end{tabular}

$\mathrm{BMI}=$ body mass index, $\mathrm{FBS}=$ fasting blood sugar

endurance capacity [22-24] of the individuals. We suspect that, the more physical and active lifestyle of rural dwellers may likely predispose them to produce an increase levels of IL-6 more than the relatively sedentary lifestyle among urban dwellers. Lifestyle variations between rural and urban

Table 3 Associations between anthropometric and pro-inflammatory markers in T2DM

\begin{tabular}{lll}
\hline Setting & $\begin{array}{l}r(p \text { value }) \\
\text { IL-6 }\end{array}$ & TNF- $a$ \\
\hline Rural & & \\
BMl & $0.1094(0.5131)$ & $0.0698(0.6773)$ \\
Body Fat \% & $0.0719(0.6679)$ & $-0.0251(0.8813)$ \\
Urban & & \\
BMl & $-0.3765(0.0258)$ & $0.1243(0.4769)$ \\
Body Fat \% & $0.0467(0.7901)$ & $0.0374(0.8312)$ \\
\hline
\end{tabular}

Adjusted for age and gender

BMI: body mass index, FBS: fasting blood sugar, IL-6: interleukin-6, TNF- a: tumour necrosis factor-alpha, $r$ : Spearman's partial correlation coefficient dwellers could possibly have contributed to the marked differences in the observed levels of IL-6.

In this study, T2DM urban cases had a significantly higher average level of TNF- $\alpha$ compared to those of rural cases. It has been established that, TNF- $\alpha$, is predominantly secreted from adipose tissues which are more among females [25]. In this study, majority of the study participants with T2DM was females and many were of urban settings. Females generally have more adipose tissues and body fat percentage with a consequential increase in body weight relative to their male counterparts. Hence, we suspect that the high TNF- $\alpha$ levels may have been contributed by the number of urban female participants with T2DM (Table 2). Various pro-inflammatory factors are known to be associated and linked with the risk of T2DM and obesity, a metabolic syndrome. However, differences in the sociodemographic characteristics result in variations in obesity among Ghanaian adults [26]. Consequently, this could explain for differences in the observed levels of TNF- $\alpha$ between the rural and urban populations. This assertion agrees with findings by Park et al. (2005) which showed a positive association of obesity and visceral adiposity with high serum concentrations of C-reactive protein, IL- 6 and TNF- $\alpha$ [27]. Also, a similar study by Goyal et al. [12] found that obese diabetics had higher levels of TNF- $\alpha$ compared to non-obese diabetics [12].

There was no significant difference between the mean values of IL- 6 and TNF- $\alpha$ among participants with T2DM and T2DM + HTN in both rural and urban settings. However, median values of IL- 6 and TNF- $\alpha$ in T2DM + HTN group compared with T2DM group suggests that co-morbidity with hypertension may possibly have a cumulative effect. Previous studies have established that lesions due to pulmonary arterial hypertension could cause activation of macrophages which subsequently secretes several cytokines including IL-6 and TNF- $\alpha[28,29]$. However, this assertion could not be advanced in our study since our sample size was relatively small and could have contributed in the values obtained.

We found in this study that BMI and TNF- $\alpha$ had a positive but weak correlation for both rural and urban settings, though not significant, but consistent with findings from previous studies $[12,30]$ which found no significant association. This positive linear relationship could be attributed to an increase in the adipose macrophages responsible for secreting TNF- $\alpha$ and the associated increase in adipose cells among persons with high BMI. However, in this study, BMI had a significant but negatively weak correlation with IL-6 in the urban T2DM group contrary to earlier findings [30, 31], which showed positive correlation implicating increase in adiposity with a rise in the levels of adipokines. This difference in our findings with these previous studies could be attributed 
to differences in the study group compositions, racial, environmental and nutritional differences.

There were some inherent limitations associated with this study including our sample size. We had fewer males with T2DM relative to the females especially in the urban setting which may have influenced the results. Moreover, there are confounders such as physical activity, infections and autoimmune diseases that could influence the levels of these pro-inflammatory biomarkers. The findings in this study have shown that rural and urban settings could affect variations in IL- 6 and TNF- $\alpha$ levels in T2DM population. Further investigations into these and other pro-inflammatory markers in specific populations is needed to ascertain their relevance both as early predictors and diagnostic cut offs for T2DM.

\section{Conclusion}

We conclude there was higher level of IL-6 among rural type 2 diabetics compared to those in urban setting whiles higher TNF- $\alpha$ level in urban than rural was found in the Ashanti region of Ghana. There was no association between anthropometric measurement and IL- 6 and TNF- $\alpha$ levels and co-morbidity of T2DM with hypertension had no effect on IL- 6 and TNF- $\alpha$ levels.

\section{Availability of data and materials}

Not applicable.

\begin{abstract}
Abbreviations
T2DM: Type 2 diabetes mellitus; IL-6: Interleukin-6; TNF- a: Tumuor necrosis factor-alpha; RODAM: Research on Obesity and Diabetes among African Migrants; NCDs: Non-communicable diseases; BMI: Body mass index; ELISA: Enzyme-linked immunosorbent assay.
\end{abstract}

\section{Competing interest}

The authors declare that there is no conflict of interests regarding the publication of this paper.

\section{Authors' contributions}

EOD conceived the study concept and participated in its design and drafting of manuscript. DDY participated in the design, coordination of study and drafting of manuscript. SND carried out laboratory analysis and drafting of the manuscript. WD carried out sampling and running of immunoassays and read the manuscript. AAAA and NA participated in the statistical analysis and interpretation of data. NYAB, FAB and SPS participated equally in the design, manuscript editing and overall concept. All authors read and approved the final manuscript.

\section{Authors' information}

Not applicable.

\section{Acknowledgements}

We would like to thank the RODAM study population for their co-operation. We would also like to thank Ernestina Awarikabey, Dominic Kanin, Caleb Osei-Wusu and the rest of the field team members for their immense role in the data collection from study participants at the field sites.

\section{Funding}

This study was funded by AG-EOD Group of KCCR, KNUST.

\section{Author details}

${ }^{1}$ Kumasi Centre for Collaborative Research in Tropical Medicine, Kwame Nkrumah University of Science and Technology (KNUST), Kumasi, Ghana.
${ }^{2}$ School of Public Health, KNUST, Kumasi, Ghana. ${ }^{3}$ Department of Biochemistry and Biotechnology, KNUST, Kumasi, Ghana. ${ }^{4}$ Ghana Health Service, Kumasi, Ashanti Region, Ghana.

Received: 17 March 2015 Accepted: 7 September 2015

Published online: 21 September 2015

\section{References}

1. Wild SH, Roglic G, Green A, Sicree R, King H. Global prevalence of diabetes: estimates for the year 2000 and projections for 2030 response to Rathman and Giani. Diabetes Care. 2004;27:2569.

2. Ginter E, Simko V. Type 2 diabetes mellitus, pandemic in 21 st century. Part of the series Advances in Experimental Medicine and Biology. Diabetes: Springer; 2013. p. 42-50. doi:10.1007/978-1-4614-5441-0_6

3. Kolb H, Mandrup-Poulsen T. The global diabetes epidemic as a consequence of lifestyle-induced low-grade inflammation. Diabetologia. 2010;53:10-20

4. Mbanya JCN, Motala AA, Sobngwi E, Assah FK, Enoru ST. Diabetes in sub-saharan africa. Lancet. 2010:375:2254-66.

5. Hall V, Thomsen RW, Henriksen O, Lohse N. Diabetes in Sub Saharan Africa 1999-2011: epidemiology and public health implications. A systematic review. BMC Public Health. 2011;11:564.

6. Donath MY, Shoelson SE. Type 2 diabetes as an inflammatory disease. Nat Rev Immunol. 2011;11:98-107.

7. Krakoff J, Funahashi T, Stehouwer CD, Schalkwijk CG, Tanaka S, Matsuzawa $Y$, et al. Inflammatory markers, adiponectin, and risk of type 2 diabetes in the Pima Indian. Diabetes Care. 2003;26:1745-51.

8. Pradhan AD, Manson JE, Rifai N, Buring JE, Ridker PM. C-reactive protein, interleukin 6, and risk of developing type 2 diabetes mellitus. JAMA. 2001;286:327-34.

9. Salomaa V, Havulinna A, Saarela O, Zeller T, Jousilahti P, Jula A, et al. Thirty-one novel biomarkers as predictors for clinically incident diabetes. PLoS One. 2010:5:e10100.

10. Nadeem A, Naveed AK, Hussain MM, Raza SI. Correlation of inflammatory markers with type 2 Diabetes Mellitus in Pakistani patients. Journal of Postgraduate Medical Institute (Peshawar-Pakistan). 2013;27(03):267-273.

11. Bertoni AG, Burke GL, Owusu JA, Carnethon MR, Vaidya D, Barr RG, et al. Inflammation and the incidence of type 2 diabetes: the Multi-Ethnic Study of Atherosclerosis (MESA). Diabetes Care. 2010;33:804-10.

12. Goyal R, Faizy AF, Siddiqui SS, Singhai M. Evaluation of TNF-alpha and IL-6 Levels in Obese and Non-obese Diabetics: Pre- and Postinsulin Effects. N Am J Med Sci. 2012;4:180-4.

13. Al-Shukaili A, AL-Ghafri S, Al-Marhoobi S, Al-Abri S, Al-Lawati J, Al-Maskari M. Analysis of inflammatory mediators in type 2 diabetes patients. Int J Endocrinol 2013;2013.

14. Agyemang C, Beune E, Meeks K, Owusu-Dabo E, Agyei-Baffour P, Aikins $A$, et al. Rationale and cross-sectional study design of the Research on Obesity and type 2 Diabetes among African Migrants: the RODAM study. BMJ open. 2014;4(3):e004877. doi:10.1136/bmjopen-2014-004877.

15. Association AD. Diagnosis and classification of diabetes mellitus. Diabetes Care. 2008;31:S55-60.

16. Lemogoum D, Seedat $Y K$, Mabadeje AF, Mendis S, Bovet $P$, Onwubere $B$, et al. Recommendations for prevention, diagnosis and management of hypertension and cardiovascular risk factors in sub-Saharan Africa. J Hypertens. 2003;21:1993-2000.

17. Na JO, Shin SY, Lim HE, Choi CU, Kim SH, Kim JW, et al. Impaired transport function of the left atrium and left atrial appendage in cryptogenic stroke patients with atrial septal aneurysm and without patent foramen ovale. Eur Heart J Cardiovasc Imaging. 2011;12:140-7.

18. Shin SY, Yong HS, Lim HE, Na JO, Choi CU, Choi Jl, et al. Total and interatrial epicardial adipose tissues are independently associated with left atrial remodeling in patients with atrial fibrillation. J Cardiovasc Electrophysiol. 2011;22:647-55.

19. Oghagbon EK, Jimoh KA, Olaosebikan O, Harbige L. Increased central adiposity may not underlie the marked elevation of IL-6 in diabetes mellitus patients in South-West, Nigeria. West Afr J Med. 2014;33:130-5.

20. Hossain M, Faruque MO, Kabir G, Hassan N, Sikdar D, Nahar Q, et al. Association of serum TNF- $a$ and IL- 6 with insulin secretion and insulin resistance in IFG and IGT subjects in a Bangladeshi population. Int J Diabetes Mellit. 2010;2:165-8. 
21. Petersen A, Pedersen B. The role of IL-6 in mediating the anti inflammatory. J Physiol Pharmacol. 2006;57:43-51.

22. Pedersen B, Steensberg A, Fischer C, Keller C, Keller P, Plomgaard P, et al. Searching for the exercise factor: is IL-6 a candidate? J Muscle Res Cell Motil. 2003;24:113-9.

23. Febbraio MA, Pedersen BK. Muscle-derived interleukin-6: mechanisms for activation and possible biological roles. FASEB J. 2002;16:1335-47.

24. Pedersen BK, Steensberg A, Schjerling P. Muscle-derived interleukin-6: possible biological effects. J Physiol. 2001;536:329-37.

25. Lutoslawska G, Malara M, Tomaszewski P, Mazurek K, Czajkowska A, Keska A, et al. Relationship between the percentage of body fat and surrogate indices of fatness in male and female Polish active and sedentary students. J Physiol Anthropol. 2014;33:10.

26. Amoah AG. Sociodemographic variations in obesity among Ghanaian adults. Public Health Nutr. 2003;6:751-7.

27. Park HS, Park JY, Yu R. Relationship of obesity and visceral adiposity with serum concentrations of CRP, TNF-a and IL-6. Diabetes Res Clin Pract. 2005;69:29-35

28. Soon E, Holmes AM, Treacy CM, Doughty NJ, Southgate L, Machado RD, et al. Elevated levels of inflammatory cytokines predict survival in idiopathic and familial pulmonary arterial hypertension. Circulation. 2010;122:920-7.

29. Stow JL, Low PC, Offenhauser C, Sangermani D. Cytokine secretion in macrophages and other cells: pathways and mediators. Immunobiology. 2009;214:601-12.

30. Fenkci S, Rota S, Sabir N, Sermez Y, Guclu A, Akdag B. Relationship of serum interleukin-6 and tumor necrosis factor alpha levels with abdominal fat distribution evaluated by ultrasonography in overweight or obese postmenopausal women. J Investig Med. 2006;54:455-60.

31. Stenlof K, Wernstedt I, Fjallman T, Wallenius V, Wallenius K, Jansson JO. Interleukin-6 levels in the central nervous system are negatively correlated with fat mass in overweight/obese subjects. J Clin Endocrinol Metab. 2003;88:4379-83.

\section{Submit your next manuscript to BioMed Central and take full advantage of:}

- Convenient online submission

- Thorough peer review

- No space constraints or color figure charges

- Immediate publication on acceptance

- Inclusion in PubMed, CAS, Scopus and Google Scholar

- Research which is freely available for redistribution 